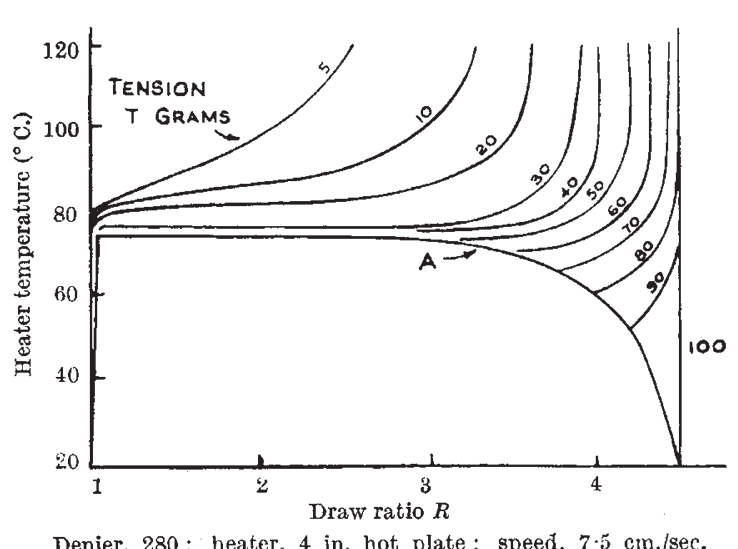

Denier, 280 ; heater, 4 in. hot plate; speed, $7.5 \mathrm{~cm} . / \mathrm{sec}$.

perature of the polymer, and drawing is then always uniform at all machine ratios.

Outside this region, where the tensions mount very rapidly, the material 'necks' at a ratio independent of the machine setting, but dependent on the diameter and initial molecular orientation of the specimen and upon the absolute speed of the machine. This is the normally observed 'cold-drawing' of the fibre. Under these conditions, the neck advances or retreats along the thread-line at a steady velocity which can be measured and used to calculate the natural draw ratio in the neck. In the graph the natural draw ratio thus calculated, for fibres of polyethylene terephthalate, is shown by the line $A$.

The natural draw ratio drops to unity at about $80^{\circ} \mathrm{C}$. in the range of the second-order transition of the polymer' ${ }^{2}$.

Consideration of the phenomenon in the terms of the surface suggests strongly to us that it is due to self-heating of the specimen to a point where the effective load-extension curve becomes horizontal; that is, to where the extension occurs at constant load but rising temperature, rather than constant temperature and rising load. Conditions for this to happen can readily be calculated for model substances having simple load-extension temperature properties, when the essential criteria for 'necking' to occur appear to be: (1) a modulus which falls with increasing temperature; (2) a sufficient rise in temperature of the material caused by the work of stretching. This in turn implies: $(a)$ poor conductivity; (b) that the work done appears as heat rather than elastic potential energy; $(c)$ that heat losses must be small. Crystallinity in the material does not appear to be essential.

Parallel observations on such substances as nylons, polyethylene, gutta percha and polymethylmethacrylate, which is amorphous, appear to support these conclusions.

We hope to publish this work elsewhere at greater length.

I. MarshaLl

A. B. THOMPSON

Plastics Division,

Imperial Chemical Industries, Ltd., Welwyn Garden City,

Herts.

July 9.

${ }^{2}$ Bunn and Alcock, Trans. Farad Soc., 41, 317 (1945). Wenderoth H., Koll. $Z$., 124, 116 (1951). Horsley and Nancarrow, Brit. $J$. App. Phys., 2, 12 (1951).

2 Kolb and Izard, J. App. Phys., 20, 564, 571 (1949).

\section{Resolution of Racemic Mixtures by Symmetrical Agents}

The recent communication by $H$. M. Powell ${ }^{1}$ on new procedures for resolution of racemic substances by means of perfectly symmetrical agents prompts me to describe my own researches on the same subject. A full account of our results, including experimental details, is to be published in the Anais Soc. Biol. Pernambuco ${ }^{2}$. Although the method outlined below is very simple, apparently it has not been mentioned in the literature ${ }^{3}$.

The proposed method is based upon the following assumptions: it is well known that optically active adsorbents preferentially adsorb one of the enantiomorphs from a racemic mixture ${ }^{4,5}$. When a crystalline racemic substance is precipitated from its solution, a crystallization nucleus is first developed. Since this nucleus contains a relatively small number of molecules there is more than an even chance that it will contain an excess of one enantiomorph or the other. Supposing that the forces acting in the growth of a crystal are of the same kind as those responsible for adsorption, this nucleus will grow proferentially, collecting one of the optical antipodes at the expense of the other, which will remain in the solution. Usually in a macro-crystal of dissymmetrical molecules obtained under perfectly symmetrical conditions the antipodal forms are so nearly equivalent in number that it is impossible by experimental means to prove the existence of an excess of one of the enantiomorphs, but this numerical equality only represents a statistical mean. It is possible, however, to increase the statistical fluctuations so that resolution can be shown.

In our experiments a racemic alkaloid, prepared synthetically (such as DL-narcotine or DL-laudonosine), insoluble in water, is first dissolved in hydrochloric acid, and a symmetrical organic base (pyridine) is then slowly poured into the solution, causing the re-precipitation of the alkaloid:

$$
\text { pyridine }+[\mathrm{BH}]+\mathrm{Cl}^{-} \rightarrow[\text { pyridine. } \mathrm{H}]+\mathrm{Cl}^{-}+B \text {. }
$$

After a small precipitate has formed, it is filtered off and the solution tested for optical activity. In our experiments with DL-narcotine and DL-laudonosine, resolutions ranging from 1 up to $2 \cdot 5$ per cent were achieved. The method can be applied to many other substances, and experiments are in progress on the resolution of DL-cystine and DL-tyrosine.

Finally, we wish to stress the implications of these findings (as well as those of Powell) on the problem of the origin of molecular dissymmetry in living matter. Processes such as those recently described are probably more likely to have occurred in the past than the activation of reactive racemic mixtures by naturally polarized light, even if they lead to a spontaneous decrease in the entropy of the system.

\section{Ricardo Carvalho Ferreira}

Faculdade de Ciencias Medicas,

Recife, Pernambuco, Brazil. Aug. 23.

'Powell, H. M., Nature, 170, 155 (1952).

2 Paper presented on July 10, 1952.

${ }^{3}$ See, for example, the exhanstive review by Ritchie, P. D., "Advances in Enzymol.", 7,65 (1947).

Henderson, G. M., and Rule, H. G., Nature, 141, 917 (1938).

Karagunis, G., and Coumoulos, G., Nature, 142, 162 (1938). 